\title{
Aircraft Gas Turbine Engine Health Monitoring System by Real Flight Data
}

\author{
Mustagime Tülin Yildirim ${ }^{1}$ and Bülent Kurt $\mathbb{D}^{2}$ \\ ${ }^{1}$ Department of Aircraft Electrical and Electronics, Faculty of Aeronautics and Astronautics, Erciyes University, \\ 38039 Kayseri, Turkey \\ ${ }^{2}$ Aircraft Technology Program, Erzincan University, 24100 Erzincan, Turkey
}

Correspondence should be addressed to Bülent Kurt; bulentkrt@gmail.com

Received 3 July 2017; Revised 7 November 2017; Accepted 10 December 2017; Published 14 March 2018

Academic Editor: Angel Velazquez

Copyright (c) 2018 Mustagime Tülin Yildirim and Bülent Kurt. This is an open access article distributed under the Creative Commons Attribution License, which permits unrestricted use, distribution, and reproduction in any medium, provided the original work is properly cited.

\begin{abstract}
Modern condition monitoring-based methods are used to reduce maintenance costs, increase aircraft safety, and reduce fuel consumption. In the literature, parameters such as engine fan speeds, vibration, oil pressure, oil temperature, exhaust gas temperature (EGT), and fuel flow are used to determine performance deterioration in gas turbine engines. In this study, a new model was developed to get information about the gas turbine engine's condition. For this model, multiple regression analysis was carried out to determine the effect of the flight parameters on the EGT parameter and the artificial neural network (ANN) method was used in the identification of EGT parameter. At the end of the study, a network that predicts the EGT parameter with the smallest margin of error has been developed. An interface for instant monitoring of the status of the aircraft engine has been designed in MATLAB Simulink. Any performance degradation that may occur in the aircraft's gas turbine engine can be easily detected graphically or by the engine performance deterioration value. Also, it has been indicated that it could be a new indicator that informs the pilots in the event of a fault in the sensor of the EGT parameter that they monitor while flying.
\end{abstract}

\section{Introduction}

Aircraft engines produce the power needed for aircraft. For this reason, aircraft engines are very important for flight safety [1]. Today's complex and advanced technology systems require advanced and expensive maintenance strategies [2]. Maintenance services are costly for airline companies. For manufacturers, maintenance is a source of revenue. According to Dennis and Kambil, though after-sales service and parts sales constitute $25 \%$ of the manufacturer's income, it makes up $40-50 \%$ of company profits [3].

Because of the high cost of maintenance, gas turbine engines must be operated within specified physical limits [4]. Today's aircraft engines are made safer by increasing the number of control parameters and sensors [5]. The engines have a complex mechanical system. Because aircraft engines operate at high temperatures, high pressures, and high speeds, there are lots of possibilities of various faults in the aircrafts [6].
Gas turbine engines show the effects of wear and tear over time. A small fault during the flight does not prevent the engine from running, but if this fault is not detected, it could lead to a bigger fault. If these bigger faults cannot be prevented in the aircraft, it can lead to high maintenance costs and accidents. When aircrafts are taken for maintenance, the condition of the gas turbine engine is investigated by various tests and measurements [7]. Condition-based maintenance (CBM) is being performed to provide effective and efficient maintenance in today's maintenance services. In the literature, there are major developments in the CBM method with studies on machine condition monitoring and fault diagnostics [8]. A typical CBM program consists of three steps [9]:

(i) Data acquisition step

(ii) Data processing step

(iii) Maintenance decision-making step 
In a CBM program, we can group two important parts as diagnostics and prognostics. With diagnostic monitoring, malfunctions or abnormal conditions are detected when a system or its subsystems are in operation [10]. With the prognostics approach, the current state of the motor and possible future failures can be predicted. The following diagnostic systems have been applied on an aircraft: the typical diagnostic procedure consists of three steps: observation, comparison, and diagnosis, which are shown in Figure 1 [11].

In the literature, advanced engine condition monitoring methods can be classified as a model-based method (such as equality equation, parameter prediction, gas path analysis, nonlinear least square, and Kalman filter) and soft computing method (such as artificial neural networks, fuzzy logic, rough sets, decision tree, and expert systems).

In the first phase of the study, some sample studies on failure prediction in gas turbine engines have been mentioned. In the second phase, the main operating parameters of the aircraft gas turbine engines and the importance of the EGT parameter are discussed. In the third phase, multiple regression analysis is performed between the EGT parameter and the aircraft performance parameters using the SPSS program. In the next phases, N1 speed, N2 speed, pitch, angle of attack, roll, vertical acceleration, total air temperature, and ground/air variables from aircraft performance parameters are taken as input parameters to the artificial neural networks, and prediction of EGT parameters has been done in MATLAB Simulink environment to monitor the condition of an aircraft gas turbine engine.

\section{Literature}

There are many studies in the literature where different methods are used to monitor the condition of gas turbine engines used on airplanes. Zhang et al. predicted failure of aircraft engines using nonlinear adaptive estimators [12], Pourbabaee et al. predicted sensor failures in gas turbine engines using multiple model-based methods [13], Zhao et al. made a prediction of failure in the gas turbine engines using fuzzy matrix and the principle of maximum membership degree [14], Afghan et al. have designed an expert system to detect faults for gas turbine combustion chambers [15], and Zaidan et al. have made failure prediction in gas turbine engines with Bayesian hierarchical models [8]. Lu and his colleagues performed a turbofan engine status monitoring with extended Kalman filter [16], Amozegar et al. have made failure prediction in gas turbine engines using dynamic neural network [17], Zhou et al. used the support vector machine method to diagnose gas turbine engine failures [18], and Chacartegui et al. have worked on real-time simulations of medium-sized gas turbines [19].

\section{Main Operation Parameters of the Engine}

There are many electronic indicators and systems that help pilots on board during flight. The pilots monitor the indicators, have knowledge of the current status of the aircraft systems, and carry out the flight. When the values appearing on the indicators indicate that they are out of the normal

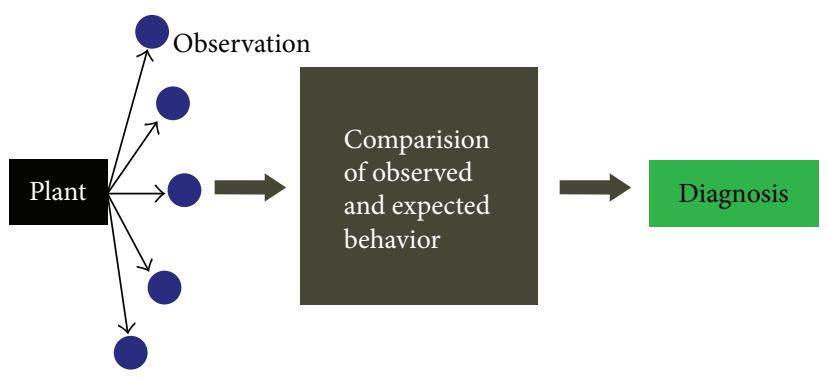

Figure 1: Typical diagnostic procedure [27].

working range or that there is a malfunction in the systems, the pilots are able to request help from the operation services via the communication systems, or in cases where they are not considered to be very serious, pilots record them in the flight book and let them be added to the maintenance program. Pilots must monitor the main operating parameters while controlling the aircraft and making decisions. In Figure 2, fan speed (N1 speed) and exhaust gas temperature (EGT), the gas turbine engine's main operating parameters, are shown. The fan speed is usually used as a push indicator, while the EGT is the parameter that allows the gas turbine engine health to be monitored. In some engine models, engine pressure ratio (EPR) and N2/N3 speed are used to monitor thrust [5]. The importance of EGT parameter is given below.

3.1. Exhaust Gas Temperature (EGT) and EGT Margin. The EGT is the temperature of the gas turbine engine's exhaust in degrees and indicates the performance status of the gas turbine engine's design. High EGT values result in further deterioration and wear in the engines. Table 1 shows which failures and causes will lead to high EGT values in engines.

In addition, pilots should pay attention to the EGT value, especially at takeoff, because exceeding the EGT limit may cause damage to the gas turbine engine components or reduce the service life of components. It is therefore important to keep the EGT as low as possible [20]. At the maximum EGT temperature, the gas turbine engines can reach at takeoff and has a certificate showing a red reference line.

An example is shown in Figure 3. The difference between the highest EGT temperature reached during the takeoff and the EGT determined by the red reference line is called EGT margin (Figure 3) [21]. EGT margin is used to obtain information about motor performance.

EGT margin deterioration is due largely to engine components. Compressor fouling, seal leakage, increased tip clearances, and airfoil erosion are among the deterioration reasons. EGT margin deterioration on airplanes causes the increase in engine thrust, the decrease in engine usage, the decrease in average flight distance, and the difficulty of the working environment. Figure 4 shows some sample faults that may increase the EGT value.

The EGT margin value is a parameter that is controlled by experts only when in maintenance at the takeoff and is used to evaluate the condition of the gas turbine engine. The more the difference between the max EGT value 


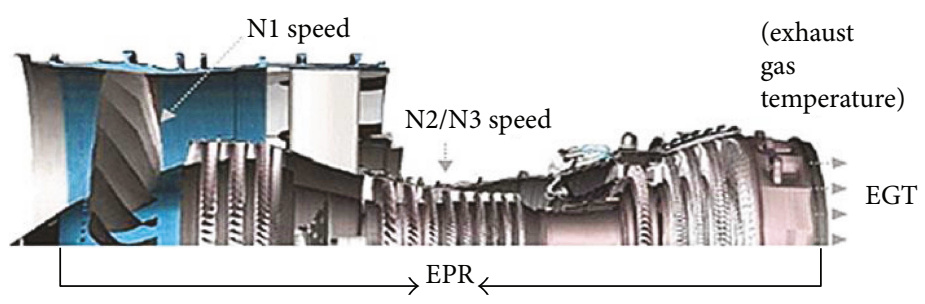

Figure 2: Main operation parameters of aircraft engines [20].

TABLE 1: Gas turbine engine failures and causes [28].

\begin{tabular}{|c|c|c|c|c|c|c|c|c|c|c|c|c|c|}
\hline & $\begin{array}{c}\text { Engine } \\
\text { separation }\end{array}$ & $\begin{array}{l}\text { Severe } \\
\text { damage }\end{array}$ & Surge & $\begin{array}{l}\text { Bird ingestion/ } \\
\text { FOD }\end{array}$ & Seizure & Flameout & $\begin{array}{c}\text { Fuel } \\
\text { control } \\
\text { problems }\end{array}$ & Fire & $\begin{array}{l}\text { Tailpipe } \\
\text { fires }\end{array}$ & $\begin{array}{l}\text { Hot } \\
\text { start }\end{array}$ & Icing & $\begin{array}{l}\text { Reverser } \\
\text { inadvertent } \\
\text { deploy }\end{array}$ & $\begin{array}{l}\text { Fuel } \\
\text { leak }\end{array}$ \\
\hline $\begin{array}{l}\text { High } \\
\text { EGT }\end{array}$ & & $\mathrm{X}$ & $\mathrm{X}$ & $\mathrm{O}$ & $\mathrm{O}$ & & $\mathrm{X}$ & & $\mathrm{O}$ & $\mathrm{X}$ & $\mathrm{O}$ & & \\
\hline
\end{tabular}

X: symptom very likely; O: symptom possible. Blank fields mean that the symptom is unlikely.

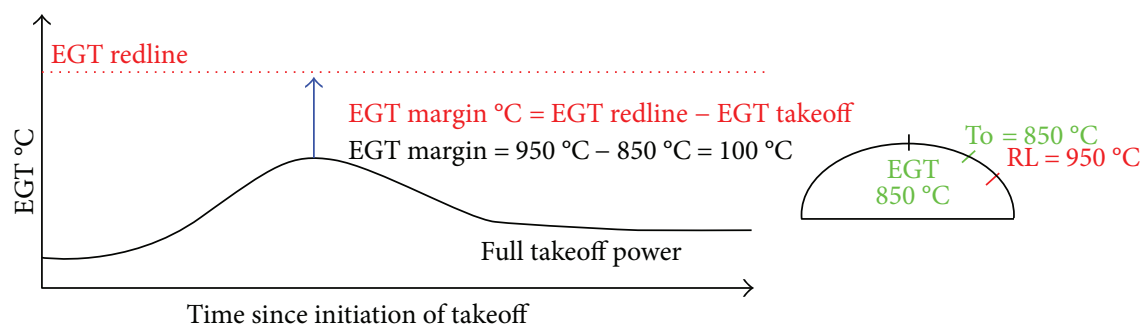

FIGURE 3: EGT margin.

reached at takeoff and the EGT redline determined by the manufacturer is, the better the performance of the gas turbine engine. This assessment is valid only for takeoff not for other flight stages.

\section{Method}

In this study, by comparing the EGT value that should be at the takeoff, cruise, and landing phase of the aircraft and the EGT value obtained from the sensor, RMS value is obtained, and this value displays the deterioration in performance. For this purpose, multiple regression analysis (MRA) and artificial neural networks (ANN) have been chosen to predict the EGT values obtained from real flight data. MATLAB program for artificial intelligence analysis and SPSS Statistics 22 package program for statistical regression analysis were used. In MRA and modeling with ANN, 12,935 samples were used. $70 \%$ for training, $15 \%$ for validation, and $15 \%$ for testing were used from these samples. The data used for modeling was recorded during the flight of the aircraft, and no changes were made to the data. Training, validation, and test data were randomly selected from the dataset. The same training, validation, and test data were used in both analyses to evaluate the comparison and modeling. The training, test, and validation data statistical parameters used in the prediction of EGT parameters are given in Tables $2-4$, respectively.

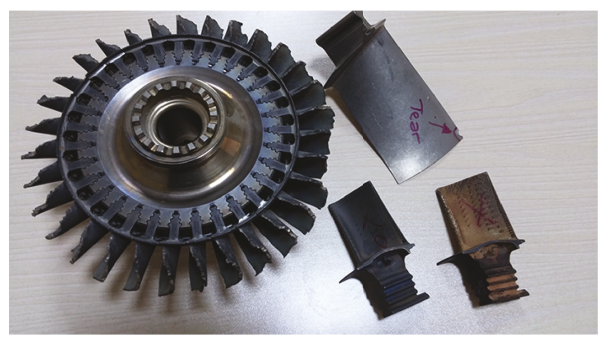

FIGURE 4: Sample faults in aircraft engines.

4.1. Statistical Regression Analysis. In the regression, the goal is to find relationships between the descriptive (independent) variables and the described (dependent) variable. As $y$ is a dependent variable, $x_{1}, x_{2}, \ldots, x_{k}$ are independent variables, the method which expresses the causal relationship between variables as a mathematical model is called a multiple linear regression model [22]. In multivariable linear regression analysis, the general formula of the regression equation that gives the shape of the relationship between variables can be expressed by

$$
y=\beta_{0}+\beta_{1} x_{1}+\beta_{2} x_{2}+\cdots+\beta_{k} x_{k}+\varepsilon,
$$

where $y, x_{1}, x_{2}, \ldots, x_{k}$ represent the observable values and $\beta_{j}$, $j=0,1, \ldots, k$, as the regression coefficients $\beta_{k}$ parameters as 
TABLE 2: Training data range used in the prediction of EGT.

\begin{tabular}{|c|c|c|c|c|c|c|c|c|c|}
\hline & \multicolumn{9}{|c|}{ Statistics } \\
\hline & N1 speed & N2 speed & Pitch & $\begin{array}{c}\text { Angle of } \\
\text { attack }\end{array}$ & Roll & $\begin{array}{c}\text { Vertical } \\
\text { acceleration }\end{array}$ & $\begin{array}{c}\text { Total air } \\
\text { temperature }\end{array}$ & Ground/air & $\begin{array}{l}\text { Exhaust gas } \\
\text { temperature }\end{array}$ \\
\hline \multicolumn{10}{|l|}{$\mathrm{N}$} \\
\hline Valid & 1005 & 1005 & 1005 & 1005 & 1005 & 1005 & 1005 & 1005 & 1005 \\
\hline Missing & 0 & 0 & 0 & 0 & 0 & 0 & 0 & 0 & 0 \\
\hline Mean & 60.9772139 & 81.6708458 & 2.112438 & 0.726965 & -0.883582 & 0.995590 & -3.034229 & 0.87 & 584.232836 \\
\hline Median & 66.9000000 & 84.4000000 & 1.100000 & -0.400000 & -1.100000 & 0.994000 & -3.300000 & 1.00 & 574.500000 \\
\hline Std. deviation & 25.43270881 & 10.67348876 & 3.9393376 & 1.7996899 & 4.1258416 & 0.0465146 & 17.7587592 & 0.341 & 116.2669986 \\
\hline Range & 75.60000 & 38.30000 & 22.9000 & 9.5000 & 51.7000 & 0.5470 & 84.8000 & 1 & 433.5000 \\
\hline Minimum & 20.40000 & 59.00000 & -3.2000 & -1.8000 & -21.8000 & 0.7750 & -24.5000 & 0 & 432.5000 \\
\hline Maximum & 96.00000 & 97.30000 & 19.7000 & 7.7000 & 29.9000 & 1.3220 & 60.3000 & 1 & 866.0000 \\
\hline
\end{tabular}

TABLE 3: Test data range used in the prediction of EGT.

\begin{tabular}{|c|c|c|c|c|c|c|c|c|c|}
\hline & \multicolumn{9}{|c|}{ Statistics } \\
\hline & N1 speed & N2 speed & Pitch & $\begin{array}{l}\text { Angle of } \\
\text { attack }\end{array}$ & Roll & $\begin{array}{c}\text { Vertical } \\
\text { acceleration }\end{array}$ & $\begin{array}{c}\text { Total air } \\
\text { temperature }\end{array}$ & Ground/air & $\begin{array}{l}\text { Exhaust gas } \\
\text { temperature }\end{array}$ \\
\hline \multicolumn{10}{|l|}{$\overline{\mathrm{N}}$} \\
\hline Valid & 215 & 215 & 215 & 215 & 215 & 215 & 215 & 215 & 215 \\
\hline Missing & 0 & 0 & 0 & 0 & 0 & 0 & 0 & 0 & 0 \\
\hline Mean & 59.8427907 & 81.3158140 & 1.969767 & 0.838140 & -1.316744 & 0.996465 & -3.040000 & 0.90 & 576.039535 \\
\hline Median & 61.9000000 & 83.1000000 & 1.100000 & .000000 & -1.100000 & 0.997000 & -2.000000 & 1.00 & 572.000000 \\
\hline Std. deviation & 25.30062671 & 10.45487550 & 3.9448260 & 1.9207515 & 3.5105979 & 0.0413821 & 17.1693103 & 0.304 & 115.2838515 \\
\hline Range & 75.60000 & 37.80000 & 21.8000 & 9.9000 & 50.3000 & 0.3550 & 53.0000 & 1 & 427.5000 \\
\hline Minimum & 20.40000 & 59.30000 & -2.8000 & -1.1000 & -21.8000 & 0.8710 & -24.5000 & 0 & 434.0000 \\
\hline Maximum & 96.00000 & 97.10000 & 19.0000 & 8.8000 & 28.5000 & 1.2260 & 28.5000 & 1 & 861.5000 \\
\hline
\end{tabular}

TABLE 4: Validation data range used in the prediction of EGT.

\begin{tabular}{|c|c|c|c|c|c|c|c|c|c|}
\hline & \multicolumn{9}{|c|}{ Statistics } \\
\hline & N1 speed & N2 speed & Pitch & $\begin{array}{l}\text { Angle of } \\
\text { attack }\end{array}$ & Roll & $\begin{array}{c}\text { Vertical } \\
\text { acceleration }\end{array}$ & $\begin{array}{c}\text { Total air } \\
\text { temperature }\end{array}$ & Ground/air & $\begin{array}{l}\text { Exhaust gas } \\
\text { temperature }\end{array}$ \\
\hline \multicolumn{10}{|l|}{$\overline{\mathrm{N}}$} \\
\hline Valid & 215 & 215 & 215 & 215 & 215 & 215 & 215 & 215 & 215 \\
\hline Missing & 0 & 0 & 0 & 0 & 0 & 0 & 0 & 0 & 0 \\
\hline Mean & 59.6409302 & 80.8041860 & 1.791628 & 0.672093 & -1.298140 & 1.000530 & -4.323721 & 0.86 & 575.411628 \\
\hline Median & 65.9000000 & 83.9000000 & 1.100000 & -.400000 & -1.400000 & 0.997000 & -8.300000 & 1.00 & 572.000000 \\
\hline Std. deviation & 25.67176527 & 10.77929528 & 3.6772253 & 1.7983021 & 4.4961766 & 0.0397756 & 17.7368312 & 0.347 & 108.3661869 \\
\hline Range & 75.30000 & 37.80000 & 22.5000 & 7.1000 & 51.0000 & 0.4170 & 64.0000 & 1 & 421.5000 \\
\hline Minimum & 20.60000 & 59.30000 & -2.8000 & -1.1000 & -21.8000 & 0.8360 & -24.0000 & 0 & 442.0000 \\
\hline Maximum & 95.90000 & 97.10000 & 19.7000 & 6.0000 & 29.2000 & 1.2530 & 40.0000 & 1 & 863.5000 \\
\hline
\end{tabular}

the expected change in $y$ for the unit changes in $x_{k}$ 's and $e$ error. The model investigated for regression analysis in this study is given in Table 5 .

Where $x_{i}$ values are, respectively, N1 speed, N2 speed, pitch, angle of attack, roll, vertical acceleration, total air temperature, ground/air, and $\beta_{0}, \beta_{1}, \beta_{2}, \beta_{3}, \beta_{4}, \beta_{5}, \beta_{6}, \beta_{7}, \beta_{8}$ are unknown parameters. The investigation of whether the coefficients of the regression model are significantly different is carried out by the $t$-test. When the significance value (Sig.) of the $t$-statistic is less than 0.05 , the assumption is accepted and it is concluded that the coefficients in the model are meaningful. Sig. value is the value used with the purpose of determining the existence of statistical significance and the level of proof of the difference, if any. The level of significance is usually taken as 0.05 and 0.01 . A level of 5\% significance means a confidence interval of $95 \%$, and a level of 
TABLE 5: Investigational model for the regression analysis.

\begin{tabular}{lr}
\hline Dependent variable $(y)$ & Independent variable $\left(x_{i}\right)$ \\
\hline Exhaust gas temperature $(\mathrm{EGT})=\beta_{0}+\beta_{1} x_{1}+\beta_{2} x_{2}+\beta_{3} x_{3}+\beta_{4} x_{4}$ \\
$+\beta_{5} x_{5}+\beta_{6} x_{6}+\beta_{7} x_{7}+\beta_{8} x_{8}$. \\
\hline
\end{tabular}

TABLE 6: The interpretation of the Sig. value [23].

\begin{tabular}{lc}
\hline Sig. value & Meaning \\
\hline $0.01<$ Sig. $\leq 0.05$ & The results are significant. \\
$0.001 \leq$ Sig. $<0.01$ & The results are highly significant. \\
Sig. $<0.001$ & The results are very highly significant. \\
$0.05 \leq$ Sig. $<0.10$ & The results are considered not \\
& statistically significant. \\
Sig. $>0.10$ & A trend toward statistical \\
& significance is sometimes noted. \\
\hline
\end{tabular}

significance of $1 \%$ means a confidence interval of $99 \%$. The general approach to the interpretation of the Sig. value is given in Table 6 [23].

4.2. Artificial Neural Networks. ANN are nonlinear modalities that are composed of artificial neurons connected with each other and that contain an input set and a single output. In ANN, there are many cells and many bonds between inputs and outputs. ANN can be divided into several subclusters. These small groups are called layers. The network is formed by hierarchically connecting layers. In ANN, learning takes place in two stages. In the first step, the random weight values are taken and the net output is determined for the sample shown to the network. The weights are regenerated by feedback or forward feed according to the response suitability. In the second step, the weight values are changed by showing different samples to the network in order to find the best weight value that the correct output can obtain. There are different algorithms used in the learning process. The backpropagation algorithm is the most common. In the backpropagation algorithm, it tried to reduce backward errors. The training algorithm specifies how to adapt the learning rule to ANN according to the nature of the problem at hand. The samples selected during training should be selected from each region of the problem space to represent the problem space. The input and corresponding output vector are used to train the network. The output obtained from each iteration result is compared to the target, and network training is continued with the weight renewal process or the training is terminated depending on the given error. After the weights, providing the best output data is determined in artificial neural networks, the processes carried out to evaluate the learning status of the network are defined as testing the network. In this phase, the output is produced by using the most suitable weight values determined after the training by introducing not seen samples to the network. This output reveals the learning success of the network. The more successful the result, the better the training performance of the network.
4.3. Measurement Accuracy of Prediction Models. The accuracy of a prediction model depends on how close the prediction values are to the actual observation value. If the model is successful in predicting actual values, the prediction error will be relatively low. The methods used in this study were analyzed by three different error performance methods. The first of these is the $R^{2}$ determination coefficient and can be expressed by

$$
R^{2}=1-\frac{\sum_{i=1}^{n}\left(y_{i}-x_{i}\right)^{2}}{\sum_{i=1}^{n}\left(y_{i}-\bar{y}\right)^{2}},
$$

where $n$ is the number of observations, $y$ is the actual values, $x$ is the predicted value, and $\bar{y}$ is the average actual value. The other error analysis method is expressed by the mean absolute percentage error (MAPE).

$$
\text { MAPE }=\frac{\sum_{i=1}^{n}\left(\left|e_{t}\right| / y_{t}\right)}{n} 100(\%) .
$$

In this formula, $e_{t}=y_{t}-x_{t}, y_{t}$ is the actual observation value, $x_{t}$ the prediction value, $n$ is number of observations in the prediction period, and $e_{t}$ is the prediction error in $t$ period. Another error analysis method is expressed by the mean square error (MSE).

$$
\mathrm{MSE}=\frac{1}{n} \sum_{i=1}^{n}\left(y_{i}-x_{i}\right)^{2},
$$

where $x_{i}$ is the predicted value of the $i$ th unit, and $y_{i}$ is the actual value of the $i$ th unit. The closer the predicted values are to the actual values, the smaller the MSE becomes; the further away from the actual values the greater the MSE is. Root mean square error (RMSE) in (5) is a frequently used measure of the differences between values (sample values) predicted by a model or an estimator and the values actually observed.

$$
\mathrm{RMSE}=\sqrt{\frac{1}{n} \sum_{i=1}^{n}\left(y_{i}-x_{i}\right)^{2}} .
$$

\section{Results and Discussions}

5.1. Determination of Effective Aircraft Performance Parameters and Prediction by Multiple Regression Analysis. Multiple regression analysis was performed to determine the effect of independent variables on dependent variable EGT parameter. When the significance value (Sig.) of $t$-statistic is greater than 0.05 in multiple regression models, the analysis is repeated by subtracting the meaningless variable from the model. A new model has been derived by subtracting meaningless variables from the data recorded during flight of the aircraft. In the obtained model, N1 speed, N2 speed, pitch, angle of attack, roll, vertical acceleration, total air temperature, and ground/air parameters were found to be important parameters affecting EGT parameter (Table 7). Here, EGT is a dependent variable, N1 speed, N2 speed, pitch, angle of attack, roll, vertical acceleration, total air temperature, and ground/air are independent variables, 
TABLE 7: Multiple regression analysis results for EGT training data.

\begin{tabular}{|c|c|c|c|c|c|c|c|c|}
\hline \multirow{3}{*}{ Model } & \multicolumn{8}{|c|}{ Coefficients $^{\mathrm{a}}$} \\
\hline & \multicolumn{2}{|c|}{$\begin{array}{l}\text { Unstandardized } \\
\text { coefficients }\end{array}$} & \multirow{2}{*}{$\begin{array}{c}\text { Standardized coefficients } \\
\text { Beta }\end{array}$} & \multirow{2}{*}{$t$} & \multirow{2}{*}{ Sig. } & \multicolumn{3}{|c|}{ Correlations } \\
\hline & $B$ & Std. error & & & & Zero order & Partial & Part \\
\hline \multicolumn{9}{|l|}{1} \\
\hline (Constant) & 854.361 & 32.679 & & 26.144 & 0.000 & & & \\
\hline N1 speed & 7.279 & 0.261 & 1.592 & 27.924 & 0.000 & 0.718 & 0.663 & 0.217 \\
\hline N2 speed & -7.605 & 0.529 & -.698 & -14.381 & 0.000 & 0.653 & -0.415 & -0.112 \\
\hline Pitch & 8.654 & 0.553 & 0.293 & 15.651 & 0.000 & 0.874 & 0.444 & 0.122 \\
\hline Angle of attack & 2.139 & 0.799 & 0.033 & 2.675 & 0.008 & -0.003 & 0.084 & 0.021 \\
\hline Roll & 1.592 & 0.238 & 0.056 & 6.687 & 0.000 & -0.139 & 0.207 & 0.052 \\
\hline Vertical acceleration & -72.026 & 20.637 & -0.029 & -3.490 & 0.001 & -0.107 & -0.110 & -0.027 \\
\hline Total air temperature & 3.418 & 0.146 & 0.522 & 23.377 & 0.000 & 0.003 & 0.595 & 0.182 \\
\hline Ground/air & -33.776 & 5.793 & -0.099 & -5.831 & 0.000 & 0.007 & -0.182 & -0.045 \\
\hline
\end{tabular}

${ }^{a}$ Dependent variable: Exhaust gas temperature.

TABLE 8: Model summary.

\begin{tabular}{|c|c|c|c|c|}
\hline Model & $R$ & $R$ square & Adjusted $R$ square & Std. error of the \\
\hline 1 & $0.969^{\mathrm{a}}$ & 0.940 & 0.939 & 28.67019 \\
\hline \multicolumn{5}{|c|}{$\begin{array}{l}\text { aPredictors: (constant), ground/air, vertical acceleration, pitch, roll, angle of att } \\
\text { gas temperature. }\end{array}$} \\
\hline \multicolumn{5}{|c|}{$\begin{array}{l}\text { TABLE 9: The interpretation of The Pearson correlation coefficient } \\
\text { [29]. }\end{array}$} \\
\hline \multicolumn{4}{|c|}{ Correlation value } & Meaning \\
\hline \multicolumn{4}{|c|}{$0.00-0.19$} & Very weak \\
\hline \multicolumn{4}{|c|}{$0.20-0.39$} & Weak \\
\hline \multicolumn{4}{|c|}{$0.40-0.59$} & Moderate \\
\hline \multicolumn{4}{|c|}{$0.60-0.79$} & Strong \\
\hline \multicolumn{4}{|c|}{$0.80-1.0$} & Very strong \\
\hline
\end{tabular}

$B$ is unregulated regression coefficient, beta is standardized regression coefficient, Sig. is significance level, $R$ is correlation coefficient, and $R^{2}$ is the determination coefficient. According to Table 8, N1 speed, N2 speed, pitch, angle of

attack, roll, vertical acceleration, total air temperature, and ground/air parameters are highly correlated with dependent variable EGT parameter $(R=0.969)$. Independent variables explain $93.9 \%$ (adjusted $R$ square $=0.939$ ) of the total variance (change) in the dependent variable EGT (see Table 8). According to the standardized regression coefficient (beta), the relative importance of the independent variables over the EGT parameter is N1 speed, total air temperature, pitch, roll, angle of attack, vertical acceleration, ground/air, and N2 speed. When the $t$-test results on the significance of regression coefficients are examined, it is seen that N1 speed parameter is the most important (significant) independent variable on EGT. According to the results of regression analysis, multiple regression equation's mathematical model for EGT prediction is expressed by

$$
\begin{aligned}
\mathrm{EGT}= & 854,361+7,279 . \mathrm{N} 1 \text { speed }-7,605 . \mathrm{N} 2 \text { speed }+8,654 . \text { Pitch }+ \text { 2, } 139 . \mathrm{AOA}+1,592 . \text { Roll } \\
& -72,026 . \text { Vertical acceleration }+3,418 . \mathrm{TAT}-33,776 . \text { Ground/air } .
\end{aligned}
$$

The analysis of the linear multiple regression model is shown in Table 7. The fact that Sig. values of the parameters used in this model are less than 0.01 means that it is a highly significant model according to Table 6.

As a result of the correlation analysis, whether there is a linear relationship and the degree of this relation if there is any is calculated by a correlation coefficient, the correlation coefficient takes values between -1 and +1 . If there is a positive correlation, the value of the variable $y$ increases as the value of the variable $x$ increases, or the value of the variable $y$ tends to decrease as the value of the variable $x$ decreases. Negative correlation (negative relationship) 
TABLE 10: ANOVA results for EGT training.

\begin{tabular}{lccccc}
\hline Model & Sum of squares & df & $\begin{array}{c}\text { ANOVA } \\
\text { Mean square }\end{array}$ & $F$ & Sig. \\
\hline 1 & & & & & \\
$\quad$ Regression & 12753394.90 & 8 & 1594174.363 & 1939.432 & $0.000^{\mathrm{b}}$ \\
$\quad$ Residual & 818692.113 & 996 & 821.980 & & \\
$\quad$ Total & 13572087.02 & 1004 & & & \\
\hline
\end{tabular}

${ }^{\mathrm{a}}$ Dependent variable: exhaust gas temperature. ${ }^{\mathrm{b}}$ Predictors: (constant), ground/air, vertical acceleration, pitch, roll, angle of attack, total air temperature, N2 speed, and N1 speed.

TABLE 11: MRA error performance values.

\begin{tabular}{lccccc}
\hline MRA & $R^{2}$ & RMSE & MAPE & \% MAPE & MSE \\
\hline Train & 0.939 & 28.67 & 0.039463 & 3.9463 & 821.98 \\
Test & 0.947038 & 26.468 & 0.038119 & 3.8119 & 700.6043 \\
Validation & 0.93702 & 27.131 & 0.036104 & 3.6104 & 736.1433 \\
\hline
\end{tabular}

means that if one of the variables increases, the value of the other variable decreases.

When the values in Table 7 are interpreted according to Table 9, it could be seen that there is a strong, positive, and significant relationship between the pitch parameter and the EGT parameter and that there is a strong positive correlation between the N1 speed and N2 speed parameters and the EGT parameter. It could also be seen that there is a very weak, positive, and significant relationship between total air temperature and ground/air parameters and EGT parameters and that the angle of attack, roll, and vertical acceleration seem to be very weak and negative and have a significant relationship.

The fact that the Sig. value shown in Table 10 (Sig. $=0.000)$ is smaller than 0.001 indicates that the developed model is very highly significant. According to 6, EGT parameter, training, test, and validation data are predicted by multiple regression analysis. The error performance values between the measured values and the predicted values for the training, test, and validation stages are determined according to 2, 3, 4, and 5. The comparison of EGT values predicted by multiple regression analysis and EGT value from the aircraft sensor at training, test, validation stage is shown in Table 11.

5.2. Prediction with Artificial Neural Network. In the ANN model; N1 speed, N2 speed, pitch, angle of attack, Roll, vertical acceleration, total air temperature, and ground/air are given as the input data to the network and EGT is predicted as the output data. All the data have been presented to the network as it was received from the aircraft without any change.

The limit values of the input and output parameters of the ANN model are shown in Tables 2-4. 12,935 data obtained from the flight of the aircraft were used in the MATLAB program with "dividerand" command $70 \%$ of which for training, $15 \%$ of which for testing, and $15 \%$ of which for validation. The feed forward network type was chosen as the artificial neural network model to be used in practice. In the feed forward calculation, the most important event is trying to predict the output values with the lowest error margin. The model shown in Figure 5 is obtained by changing the number of iterations and the number of neurons in the hidden layer for the optimal network architecture for predicting the EGT parameter with the experiments performed. The best results of 11 different training functions to predict the EGT parameter with the smallest error are shown in Table 12. For experiments, a computer with Intel (R) Core (TM) i5-4590 CPU @ 3.30 GHz 4 GB RAM was used.

When the results in Table 12 are compared against the test MSE value, it is determined that the LevenbergMarquardt backpropagation function (trainlm) is the best resultant. In Figures 6-8, it illustrates neural network regression plots for training, validation, and test. The correlation coefficient of the EGT value from the aircraft sensor and the predicted values of training, test, and validation phases are higher $(R>0.99)$. In order to evaluate the performance of the developed network, the error performance values between measured values and predicted values for training, validation, and test phases were determined according to 2, 3, 4, and 5 and the results are presented in Table 13. In addition, the network characteristics developed are given in Table 14.

When the results are evaluated, determination coefficient $\left(R^{2}>0.99\right)$ could explain more than $99 \%$ of EGT parameter at training, testing, and the validation stage with $\mathrm{N} 1$ speed, N2 speed, pitch, angle of attack, roll, vertical acceleration, total air temperature, ground/air parameters. The closer the $R^{2}$ parameter is to 1 , the better the performance of the network. Lewis has classified the models with a MAPE value of less than $10 \%$ as "very good," models between $10 \%$ and $20 \%$ as "good," models between $20 \%$ and $50 \%$ as "acceptable," and models higher than $50 \%$ as "wrong and faulty" $[24,25]$. When we look at the MAPE values of the enhanced network, it is suggested that the network is predicated on high accuracy since MAPE is $<1 \%$ during the training, testing, and validation phases. It also indicates that the smaller the RMSE parameter, the higher the performance of the network.

5.3. Modeling of the Engine Health Monitoring Program in MATLAB Simulink Environment. In order for our system to work instantly, we need to design an interface in the MATLAB Simulink environment with the best ANN model we have obtained as a result of the experiments. Figure 9 shows the structure of the ANN model modeled in MATLAB Simulink environment. 


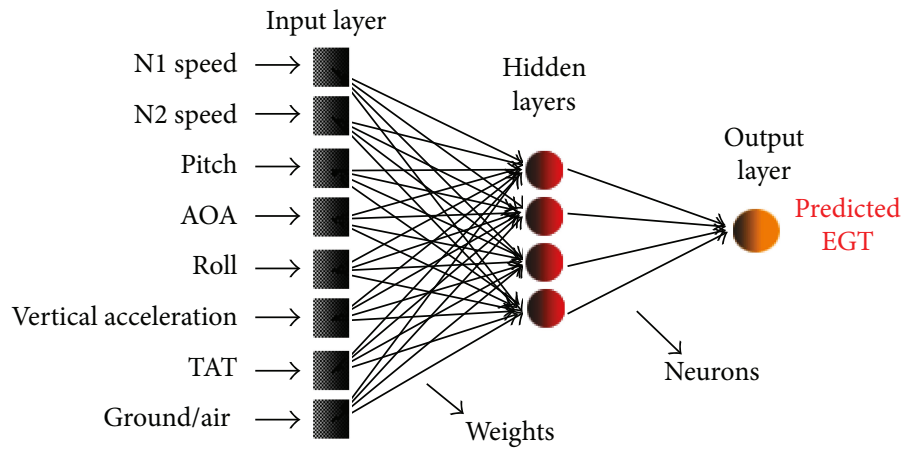

FIGURE 5: Architecture of the proposed neural model.

TABLE 12: Comparison of the feedforward neural network training algorithms for their test MSE value.

\begin{tabular}{|c|c|c|c|c|c|c|}
\hline Training algorithm & Elapsed time (sec) & Training $R$ & Validation $R$ & Test $R$ & Training MSE & $\overline{\text { Test MSE }}$ \\
\hline trainlm & 4.203957 & 0.99767 & 0.99797 & 0.99719 & 62.8501 & 74.6465 \\
\hline traincgb & 4.565835 & 0.99586 & 0.99299 & 0.99656 & 111.4932 & 91.2834 \\
\hline trains & 10.047608 & 0.99561 & 0.99517 & 0.99653 & 118.4071 & 91.8717 \\
\hline trainrp & 57.118179 & 0.99458 & 0.99297 & 0.9963 & 146.1263 & 97.9763 \\
\hline traincgp & 3.699402 & 0.99401 & 0.99515 & 0.99501 & 161.8084 & 133.9647 \\
\hline trainscg & 3.458904 & 0.99381 & 0.99084 & 0.99474 & 166.9843 & 139.1074 \\
\hline trainbfg & 13.748363 & 0.99213 & 0.99176 & 0.99394 & 211.9474 & 160.1871 \\
\hline traincgf & 7.667996 & 0.99179 & 0.99176 & 0.99395 & 222.3323 & 164.4613 \\
\hline trainoss & 4.432661 & 0.99053 & 0.99197 & 0.99183 & 255.8224 & 215.3883 \\
\hline traingdx & 3.614869 & 0.98838 & 0.98893 & 0.9893 & 312.1862 & 285.3237 \\
\hline traingda & 4.008302 & 0.98312 & 0.98418 & 0.98733 & 459.2168 & 342.6505 \\
\hline
\end{tabular}

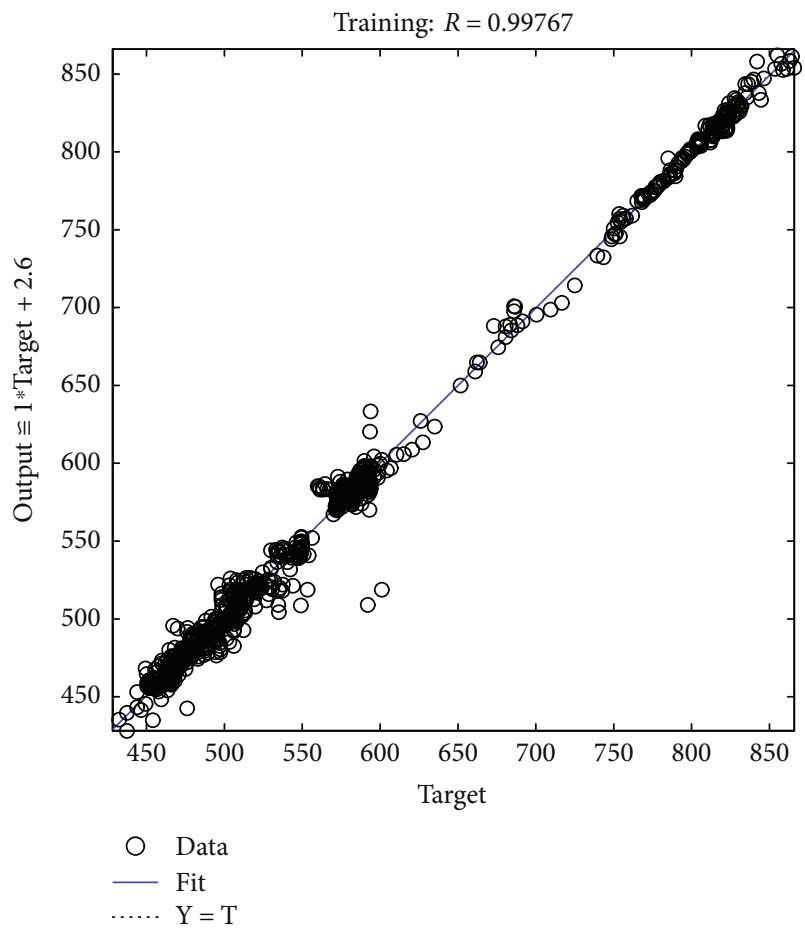

Figure 6: Neural network regression plots for training.

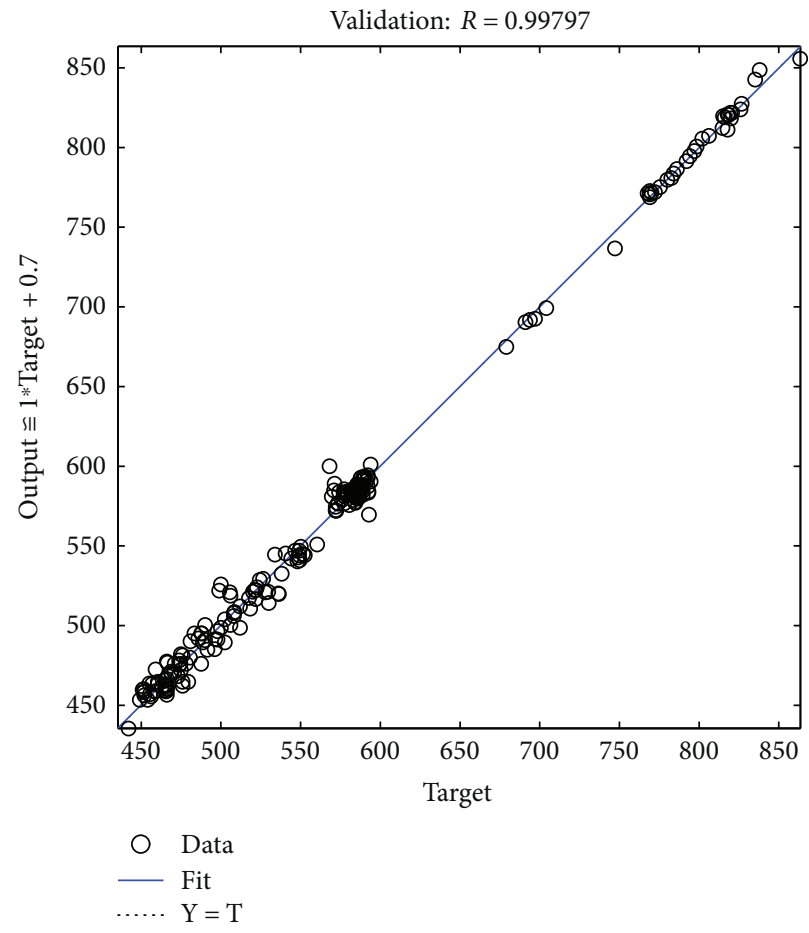

Figure 7: Neural network regression plots for validation. 


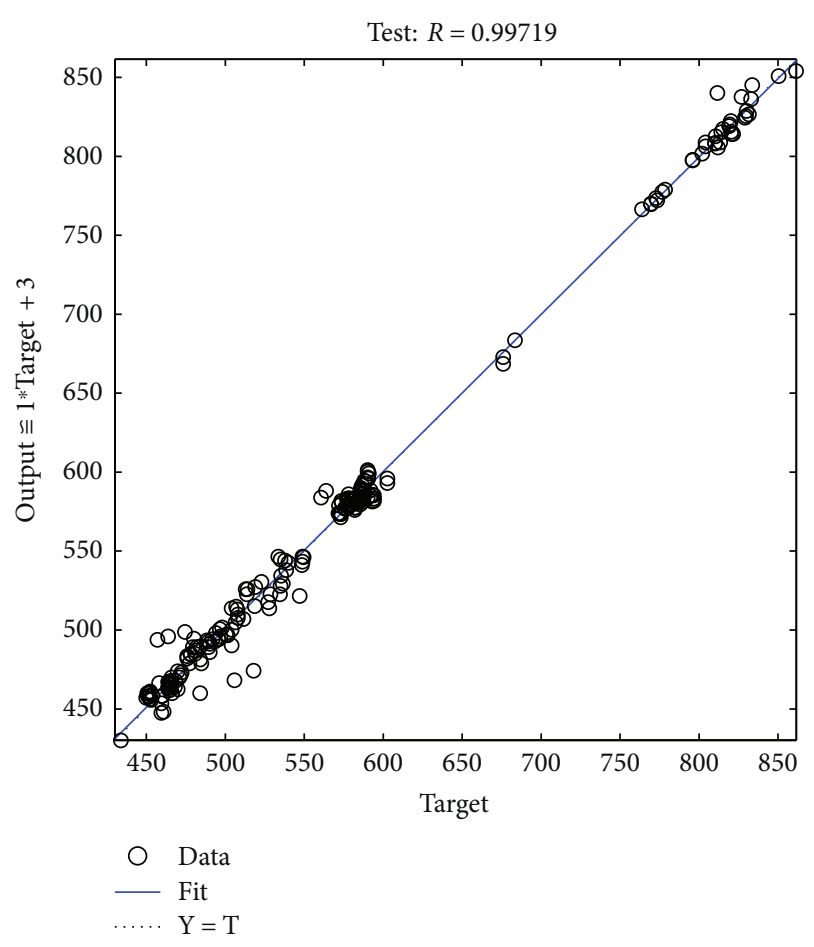

Figure 8: Neural network regression plots for test.

TABLE 13: ANN error performance values (fsor trainlm).

\begin{tabular}{lcccc}
\hline ANN & $R^{2}$ & MAPE & \% MAPE & RMSE \\
\hline Train & 0.99534601 & 0.00917102 & 0.917102 & 7.927808 \\
Test & 0.99435716 & 0.002224188 & 0.2224188 & 8.639823 \\
Validation & 0.99594228 & 0.001924502 & 0.192450201 & 6.886876 \\
\hline
\end{tabular}

Babbar et al. evaluated the difference between EGT temperature and flight parameters of two symmetric engines at various stages of the flight to examine the condition of the aircraft [26]. By differential analysis, it is aimed to compare EGT value obtained from ANN with real EGT value coming from the sensor of the aircraft and to easily notice when there is any problem. In this study, it is necessary to instantly compare the values in order to evaluate the condition of the gas turbine engine. In this analysis, EGT.1 was determined as the actual EGT value from the sensor of aircraft and EGT.2 was determined as the parameter predicted by ANN. The similarity scale used to determine the status of the gas turbine engine is illustrated in

$$
\mathrm{EGT}_{\text {diff }}(i)=(\operatorname{EGT} .1(i)-\operatorname{EGT} .2(i))^{2} .
$$

Using EGT differences of each value, 8 is used to calculate the mean square root of the given flight phase.

$$
\mathrm{RMS}_{\text {Flightmode }}=\sqrt{\frac{1}{n} \sum_{i=1}^{n} \mathrm{EGT}_{\text {diff }}(i) .}
$$

The RMS value is shown as THE aircraft's performance deterioration value in the interface program.
Differential analysis model needs to be modeled in MATLAB Simulink environment. The interface designed for the aircraft's engine health monitoring in the MATLAB Simulink environment is shown in Figure 10.

When the graph shown in Figure 11 is examined, the values shown in the pink color represent the data obtained from the sensor of the aircraft, the values shown in the yellow color represent the EGT values predicted by the ANN, and the values shown in green indicate the motor performance.

The limit determined for the alarm level is shown in red. The alarm level assumed for this aircraft engine is EGT margin value. In order to make a system monitoring, values obtained from the system needs to be used. Two types of data are used in the applications:

(1) Data gathered from normal and faulty operation conditions.

(2) Data gathered only from monitoring of normal conditions. Collecting faulty data from gas turbine engines like systems are very difficult and expensive. Due to aviation rules like EASA Part-M, aircrafts with only a completed maintenance and with a Certificate of Release to Service are allowed to fly. An aircraft with a completed maintenance means a collection of systems with a healthy operation. Therefore, condition monitoring systems are constructed only for normal flight data.

Since we used data from a real aircraft, only normal operation data is in hand. It is apparent from simulation results that instantaneous performance of the gas turbine engine can be monitored from takeoff to landing. In this study, we compare EGT values one from instant prediction we did and another gathered from the EGT sensor of the aircraft. Even though there exists a difference in between, this is evaluated as an abnormal situation.

In Figure 12, a fault detection example is shown. Gas turbine engines are composed of various components. A failure on a single or multiple components will result in a performance defection in those engines. Corrosion, oxidation, damaged bearings, high blade clearance, damaged or burned turbine blade and vanes, damaged combustors, damaged fuel nozzles, and broken rotor discs and blades are some of the failures that lead to performance degradation. Performance degradation will result a change in EGT value. This study is not supposed to determine where and why a failure has occurred. Exceeding EGT margin $\left(+100^{\circ} \mathrm{C}\right)$ is considered as an abnormal situation. In this study, it is shown that the performance of the aircraft can be monitored from takeoff to landing.

Pilots follow various parameters during operation of the aircraft. EGT parameter is one controlled during the takeoff. Engine manufacturers determine maximum EGT thresholds during a takeoff. If the pilot does not track EGT, there is no a secondary system that generates warnings. If the engine exceeds the maximum allowed EGT values, it will experience serious failures with high probability. The system developed in this study will warn the pilot in case he misses the EGT value from the engine and warning display system. 
TABLE 14: Details of the neural model.

\begin{tabular}{|c|c|}
\hline Network parameters & Details \\
\hline \multirow[t]{2}{*}{ Architecture } & 8 inputs, 1 outputs, and 4 hidden layers with $11,8,4$, and 3 neurons in each layer (11-8-4-3) \\
\hline & Training subset: $70 \%$ randomly selected recorded data (9045 patterns) \\
\hline \multirow[t]{2}{*}{ Set } & Validation subset: $15 \%$ randomly selected recorded data (1935 patterns) \\
\hline & Test subset: $15 \%$ randomly selected recorded data (1935 patterns) \\
\hline Activation & For hidden layers: tangent sigmoid tangent \\
\hline Function & For output layer: linear \\
\hline Training algorithm & Levenberg-Marquardt \\
\hline Performance function criteria & Minimum MSE \\
\hline Stopping & Validation stop \\
\hline Criteria & (Training is stopped when the validation error starts increasing) \\
\hline
\end{tabular}

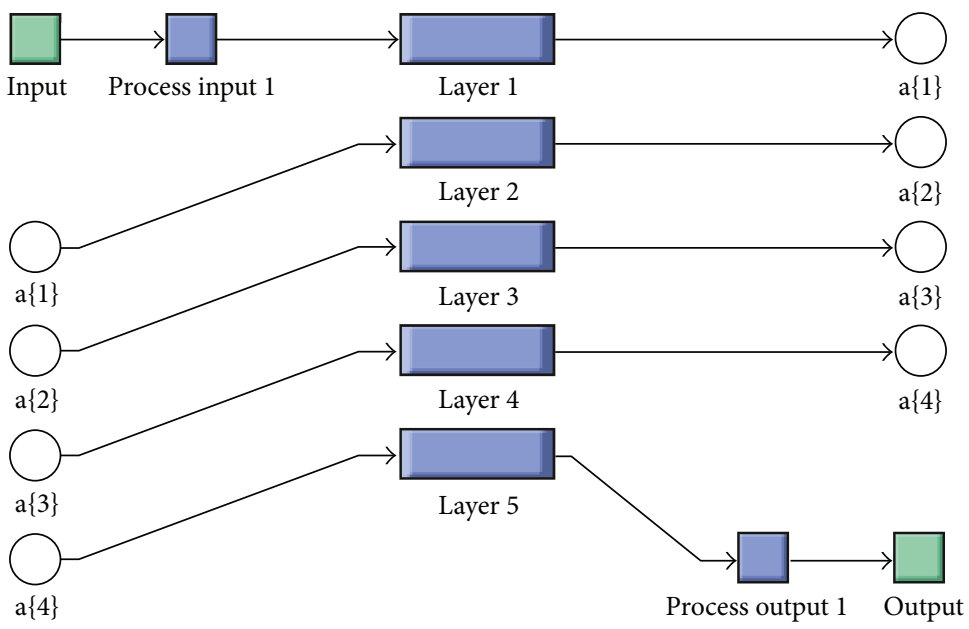

FIgURE 9: Modelling of the developed ANN model in MATLAB Simulink environment.

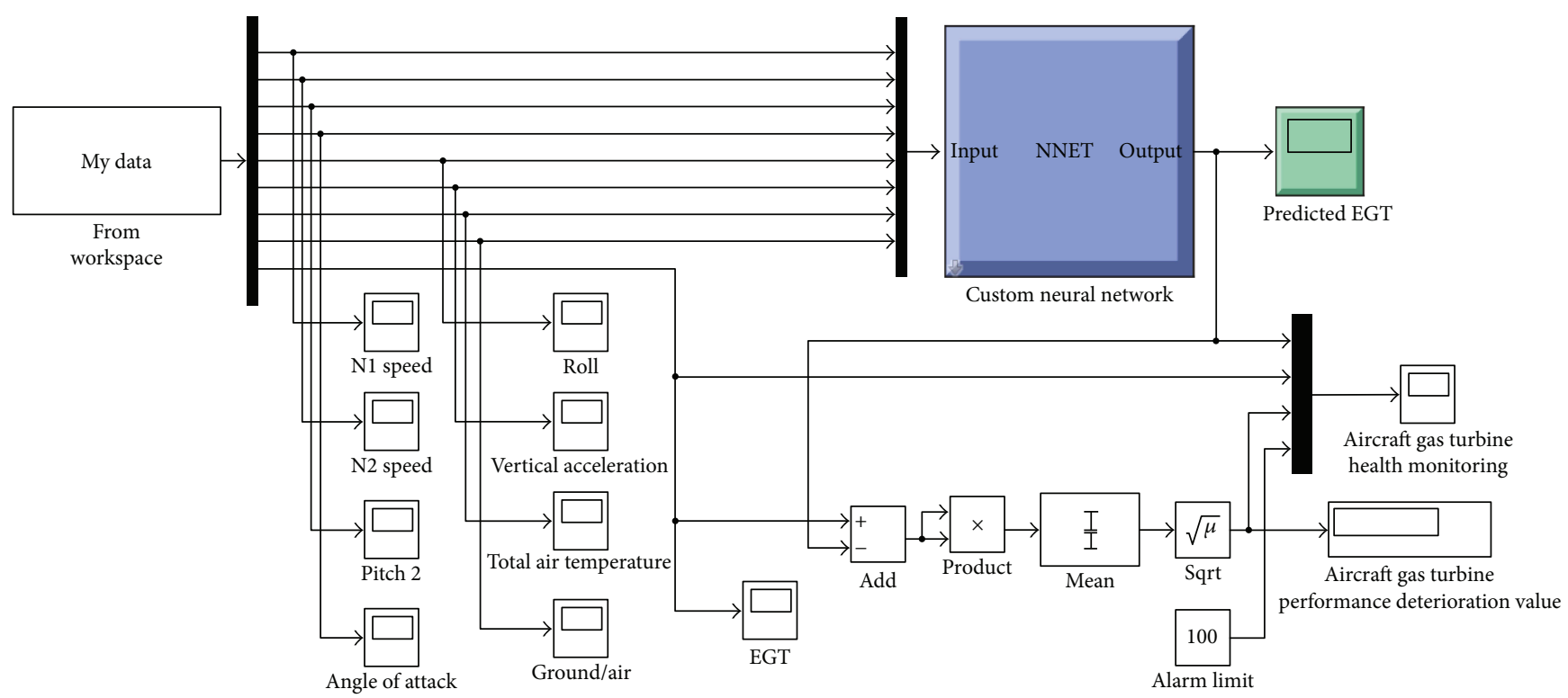

FIGURE 10: Aircraft gas turbine engine health monitoring models. 


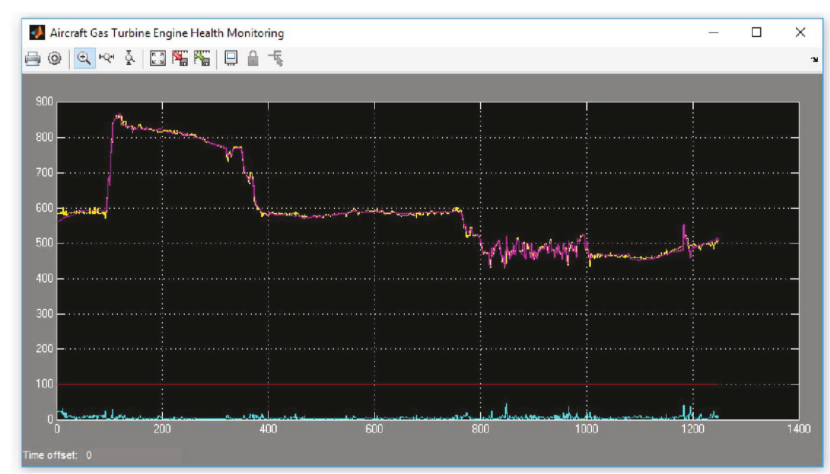

Figure 11: Results.

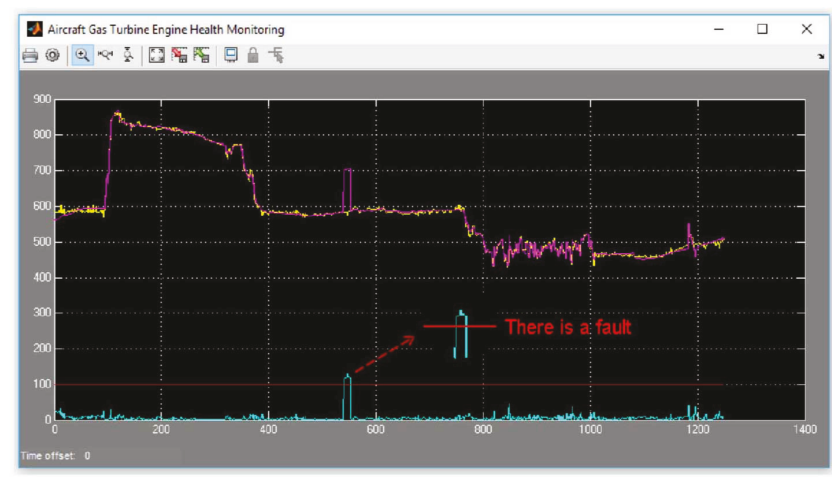

FIgURE 12: Graphical representation of an unusual EGT increase.

\section{Conclusions}

In this study, we aimed to develop a predictive model of the EGT parameter using statistical and artificial intelligence methods from the actual data recorded from the takeoff to the landing of an aircraft. Statistical multiple regression analysis and artificial neural networks were used in the prediction model and the method that gave the lowest error performance was tried to be determined. The $R^{2}$, MAPE, and RMSE values between the measured values and the predicted values for the training, validation, and test data of the EGT parameter are presented in Tables 11 and 13. When we look at the test-stage determination coefficient and error rates between the EGT values from the aircraft's sensor and the predicted EGT data, it is seen that the best end result is obtained by ANN. With the interface we developed in MATLAB Simulink, a model has been developed to instantly monitor the flight status of the aircraft.

In this study, it has been shown that any deterioration of performance can be easily detected by predicting the EGT parameter at the takeoff, cruise, and landing phases of the aircraft. Also, even if there is no fault in the aircraft's engine, a fault in the EGT sensor can jeopardize flight safety. It is thought that the pilot can fly safely with the predicted EGT value in the developed interface.

\section{Abbreviations}

ANN: Artificial neural network

AOA: Angle of attack
CBM: Condition-based maintenance

EGT: Exhaust gas temperature

EHM: Engine health monitoring

FOD: Foreign object damage

MAPE: Mean absolute percentage error

MRA: Multiple regression analysis

MSE: Mean square error

$R^{2}: \quad R$ squared

RMSE: Root mean square error

TAT: Total air temperature.

\section{Conflicts of Interest}

The authors declare that they have no conflicts of interest.

\section{Acknowledgments}

This work was supported by Research Fund of the Erciyes University, Project no. FDK-2016-6803.

\section{References}

[1] A. J. Volponi, "Gas turbine engine health management: past, present, and future trends," Journal of Engineering for Gas Turbines and Power, vol. 136, no. 5, article 051201, 2014.

[2] S. H. Kim, M. A. Cohen, and S. Netessine, "Performance contracting in after-sales service supply chains," Management Science, vol. 53, no. 12, pp. 1843-1858, 2007.

[3] M. J. Dennis and A. Kambil, "Service management: building profits after the sale," Supply Chain Management Review, vol. 7, no. 3, pp. 42-48, 2003.

[4] B. Yu, D. Liu, and T. Zhang, "Fault diagnosis for micro-gas turbine engine sensors via wavelet entropy," Sensors, vol. 11, no. 12, pp. 9928-9941, 2011.

[5] S. Garg, K. Schadow, W. Horn, H. Pfoertner, and I. Stiharu, "Sensor and actuator needs for more intelligent gas turbine engines," ASME Turbo Expo 2010: Power for Land, Sea, and Air, 2010, pp. 155-167, Glasgow, UK, June 14-18, 2010.

[6] H. Xu, D. Jiang, and L. Liang, "Application of fuzzy-rough set theory and improved SMO algorithm in aircraft engine vibration fault diagnosis," in Proceedings of the IEEE 2012 Prognostics and System Health Management Conference (PHM-2012 Beijing), pp. 1-6, Beijing, China, 2012.

[7] S. M. Lee, T. S. Roh, and D. W. Choi, "Defect diagnostics of SUAV gas turbine engine using hybrid SVM-artificial neural network method," Journal of Mechanical Science and Technology, vol. 23, no. 2, pp. 559-568, 2009.

[8] M. A. Zaidan, A. R. Mills, R. F. Harrison, and P. J. Fleming, "Gas turbine engine prognostics using Bayesian hierarchical models: a variational approach," Mechanical Systems and Signal Processing, vol. 70-71, pp. 120-140, 2016.

[9] A. K. Jardine, D. Lin, and D. Banjevic, "A review on machinery diagnostics and prognostics implementing condition-based maintenance," Mechanical Systems and Signal Processing, vol. 20, no. 7, pp. 1483-1510, 2006.

[10] T. Brotherton, G. Jahns, J. Jacobs, and D. Wroblewski, "Prognosis of faults in gas turbine engines. In aerospace conference proceedings, 2000," in 2000 IEEE Aerospace Conference. Proceedings (Cat. No.00TH8484), vol. 6, pp. 163-171, Big Sky, MT, USA, 2000. 
[11] X. Wang, Aircraft Fuel System Prognostics and Health Management [M.S. Thesis], Cranfield University, Bedfordshire, UK, 2012.

[12] X. Zhang, L. Tang, and J. Decastro, "Robust fault diagnosis of aircraft engines: a nonlinear adaptive estimation-based approach," IEEE Transactions on Control Systems Technology, vol. 21, no. 3, pp. 861-868, 2013.

[13] B. Pourbabaee, N. Meskin, and K. Khorasani, "Sensor fault detection, isolation, and identification using multiple-modelbased hybrid Kalman filter for gas turbine engines," IEEE Transactions on Control Systems Technology, vol. 24, no. 4, pp. 1184-1200, 2016.

[14] X. F. Zhao, Y. B. Liu, and X. He, "Fault diagnosis of gas turbine based on fuzzy matrix and the principle of maximum membership degree," Energy Procedia, vol. 16, pp. 1448-1454, 2012.

[15] N. H. Afgan, M. G. Carvalho, P. A. Pilavachi, A. Tourlidakis, G. G. Olkhonski, and N. Martins, "An expert system concept for diagnosis and monitoring of gas turbine combustion chambers," Applied Thermal Engineering, vol. 26, no. 7, pp. 766-771, 2006.

[16] F. Lu, J. Huang, and Y. Lv, "Gas path health monitoring for a turbofan engine based on a nonlinear filtering approach," Energies, vol. 6, no. 1, pp. 492-513, 2013.

[17] M. Amozegar and K. Khorasani, "An ensemble of dynamic neural network identifiers for fault detection and isolation of gas turbine engines," Neural Networks, vol. 76, pp. 106-121, 2016.

[18] D. Zhou, H. Zhang, and S. Weng, "A new gas path fault diagnostic method of gas turbine based on support vector machine," Journal of Engineering for Gas Turbines and Power, vol. 137, no. 10, article 102605, 2015.

[19] R. Chacartegui, D. Sánchez, A. Munoz, and T. Sánchez, "Real time simulation of medium size gas turbines," Energy Conversion and Management, vol. 52, no. 1, pp. 713-724, 2011.

[20] S. Ackert, Elements of Turbofan Shop Maintenance Costs, p. 1-42, 2011.

[21] M. T. Yildirim and B. Kurt, "Engine health monitoring in an aircraft by using Levenberg-Marquardt feedforward neural network and radial basis function network," in 2016 International Symposium on INnovations in Intelligent SysTems and Applications (INISTA), pp. 1-5, Sinaia, Romania, 2016.

[22] H. A. Es, F. Y. Kalender, and C. Hamzacebi, "Forecasting the net energy demand of Turkey by artificial neural networks," Journal of the Faculty of Engineering and Architecture of Gazi University, vol. 29, no. 3, pp. 495-504, 2014.

[23] B. Rosner, Fundamentals of Biostatistics, Brooks/Cole, Boston, MA, USA, 7th edition, 2010.

[24] C. D. Lewis, Industrial and Business Forecasting Methods, Butterworths Publishing, London, 1982.

[25] Ş. Yurtcu and A. Özocak, "Prediction of compression index of fine-grained soils using statistical and artificial intelligence methods," Journal of the Faculty of Engineering and Architecture of Gazi University, vol. 31, no. 3, pp. 597-608, 2016.

[26] A. Babbar, V. L. Syrmos, E. M. Ortiz, and M. M. Arita, "Advanced diagnostics and prognostics for engine health monitoring," in 2009 IEEE Aerospace conference, pp. 1-10, Big Sky, MT, USA, 2009.
[27] A. Patterson-Hine, G. Biswas, G. Aaseng, S. Narasimhan, and K. Pattipati, "A review of diagnostic techniques for ISHM applications," in 1st integrated systems health engineering and management forum, 2005, Napa, CA, USA, 2005.

[28] Federal Aviation Administration, "Airplane turbofan engine operation and malfunctions basic familiarization for flight crews," 2016, http://www.faa.gov/aircraft/air_cert/design_ approvals/engine_prop/media/engine_malf_famil.pdf.

[29] A. Beldjazia and D. Alatou, "Precipitation variability on the massif forest of Mahouna (North Eastern-Algeria) from 1986 to 2010," International Journal of Management Sciences and Business Research, vol. 5, no. 3, 2016. 


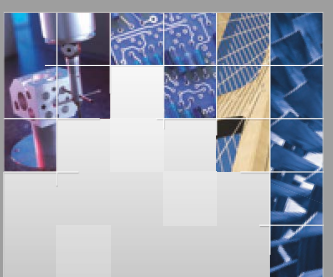

\section{Enfincering}
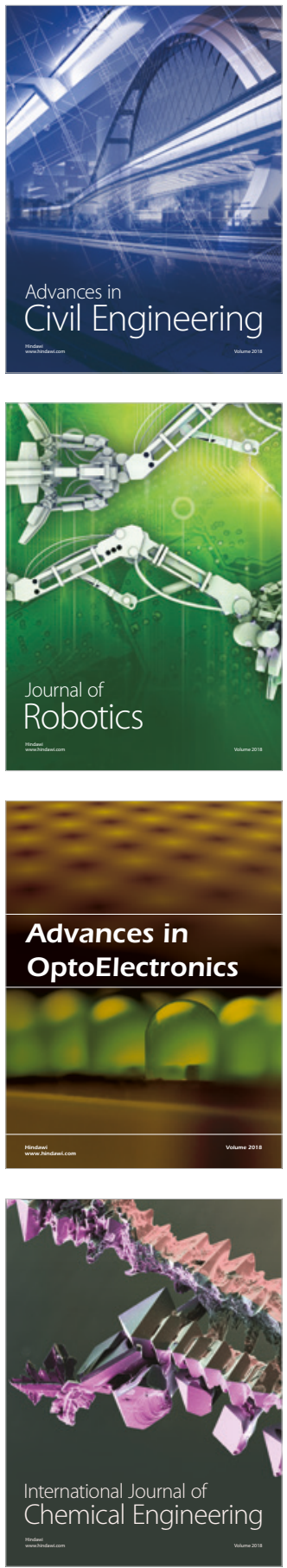

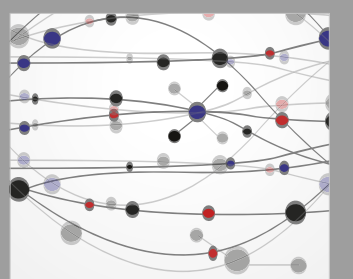

\section{Rotating \\ Machinery}

The Scientific World Journal

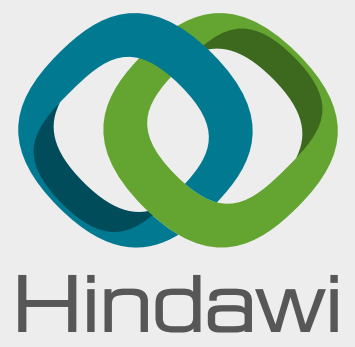

Submit your manuscripts at

www.hindawi.com
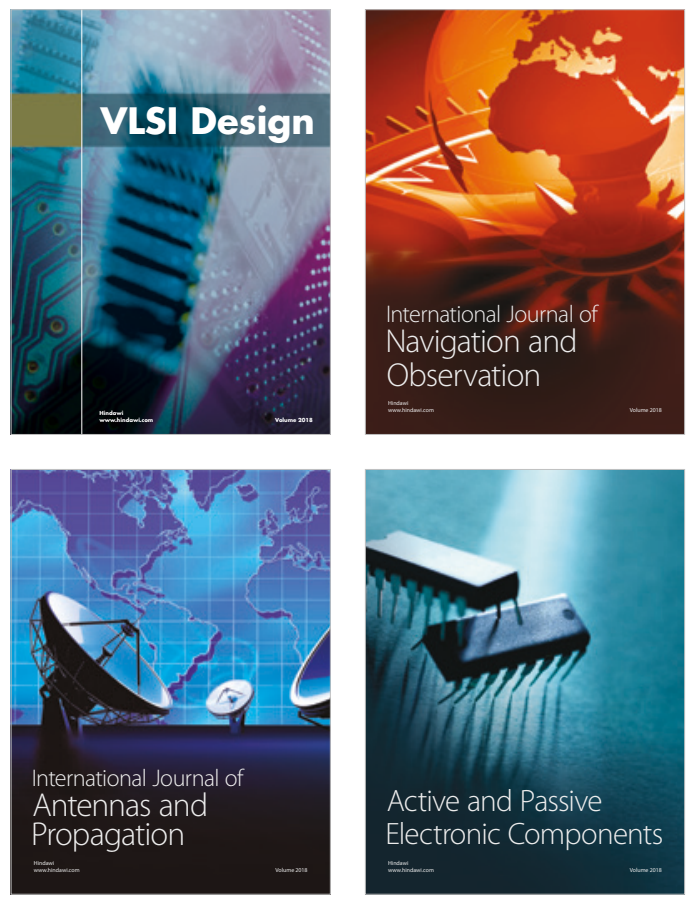
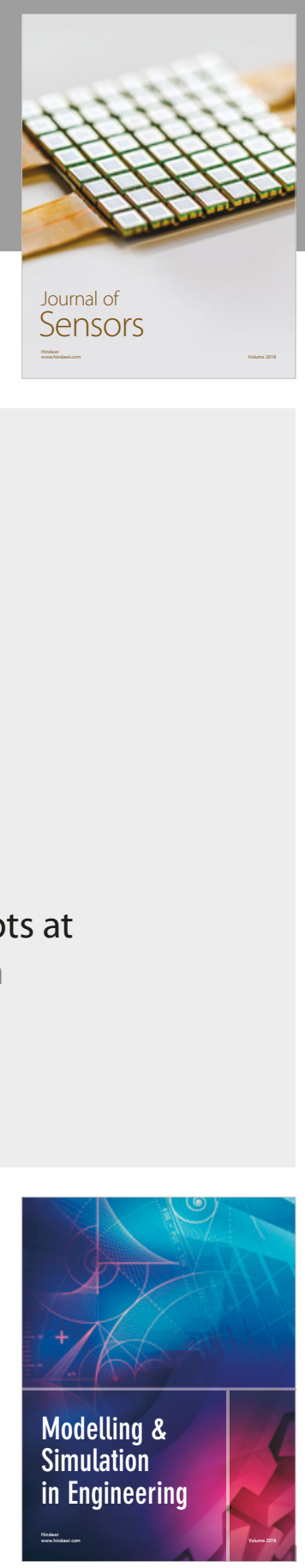

\section{Advances \\ Multimedia}
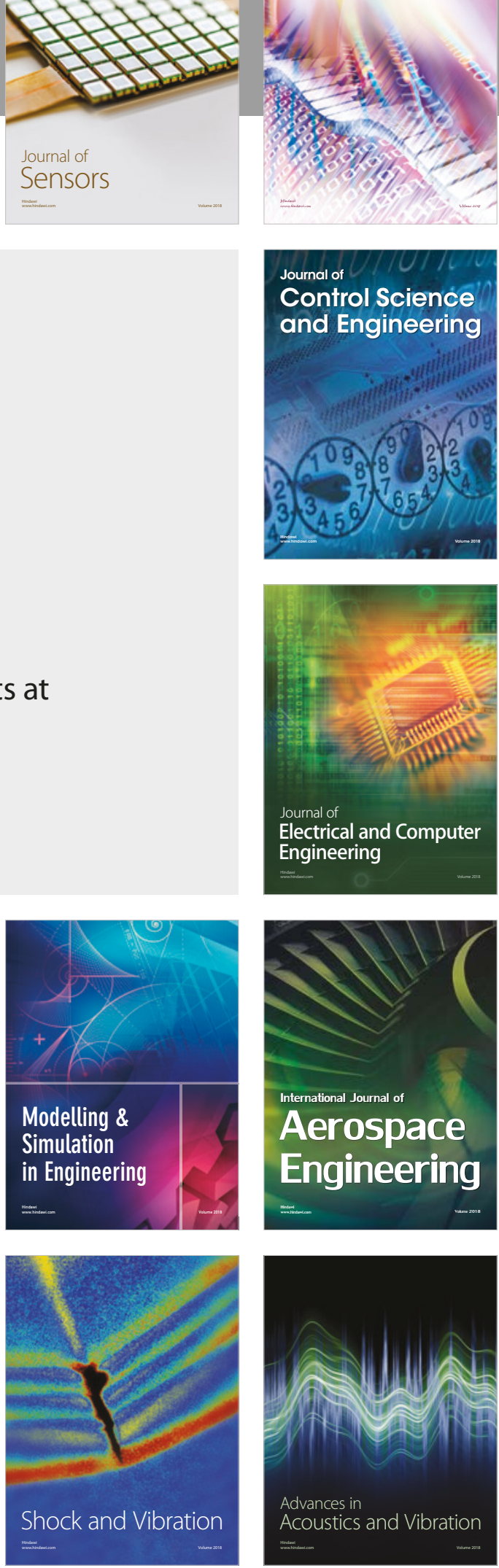